\title{
Orta Anadolu Bölgesi (Türkiye) ve civarındaki güncel deprem aktivitesinin sismik durgunluk ve magnitüd-deprem sayısı istatistiği
}

\author{
Serkan ÖZTÜRK 18 \\ ${ }^{1}$ Jeofizik Mühendisliği, Mühendislik ve Doğa Bilimleri Fakültesi, Gümüşhane Üniversitesi, Gümüşhane, Türkiye \\ 凹: serkanozturk@gumushane.edu.tr 1 0000-0003-1322-5164
}

Geliş (Received): 13.09.2019Ｄüzeltme (Revision):09.10.2019～Kabul (Accepted): 16.10.2019

\begin{abstract}
ÖZ
Bu çalışmada, Türkiye'nin Orta Anadolu Bölgesi ve civarındaki güncel deprem aktivitesinin sismik durgunluk ve magnitüd-deprem sayısı istatistikleri gerçekleştirilmiştir. Son yıllardaki güçlü/büyük deprem oluşumları nedeniyle bu bölgedeki depremsellik çalışmaları oldukça önem kazanmıştır. $b$-değeri 2002 yılından sonra bir azalma eğilimi göstermektedir ve 2019 'un başında $1.58 \pm 0.03$ 'ten $1.25 \pm 0.05$ 'e düşmüştür. $b$-değerinin bölge-zaman dağılımları, güney, batı, kuzeybatı ve güneybatı yönleri boyunca NF ve civarında, MFZ, KKFZ ve KOFZ arasında, kuzeybatı yönü boyunca SRF ve civarında, SRF ile DAFZ arasında önemli değişimler göstermektedir. 2019 y1lı başlangıcındaki sismik durgunluk bölgeleri, TGFZ'nin kuzeybatı sonlarını ve AF'yi içeren çalışma alanını, SF'nin kuzeydoğusunu, SF ile OAFS arasını, OAFS'nin kuzeydoğu kısımlarını, MF'nin batısını, SRF ile DAFZ arasını, TGFZ'nin güneydoğu sonunu, KKFZ ve civarını, Tuzgölü'nün güneybatısını içermektedir. Sonuç olarak, Bu bölgeler, gelecekteki güçlü/büyük depremler için en olası alanlardan birisi olarak düşünülebilir.
\end{abstract}

Anahtar Kelimeler: $b$-değeri, deprem potansiyeli, sismik durgunluk, sismik tehlike

\section{Seismic quiescence and magnitude-frequency statistics of current earthquake activity in the Central Anatolian Region (Turkey) and its vicinity}

\begin{abstract}
In this study, seismic quiescence and magnitude-frequency statistics of current seismic activity in and around the Central Anatolian Region of Turkey were achieved. Seismicity studies in this region have gained considerable importance due to the strong/large earthquake occurrences in recent years. $b$-value shows a tendency to decrease after 2002 and decreases from $1.58 \pm 0.03$ to $1.25 \pm 0.05$ at the beginning of 2019 . Region-time distribution of $b$-value shows significant changes in NF and its vicinity along the south, west, northwest and southwest directions, among MFZ, KKFZ and KOFZ, in and around SRF and along its northwest direction, between SRF and EAFZ. Seismic quiescence regions at the beginning of 2019 consist the northwest ends of TGFZ and study area including AF, the northeast of SF, between SF and CAFS, the northeast parts of CAFS, the west of MF, between SRF and EAFZ, the southeast end of TGFZ, KKFZ and its vicinity, the southwest of Tuzgölü. Consequently, these regions may be considered as one of the most likely areas for future strong/large earthquakes.
\end{abstract}

Keywords: $b$-value, earthquake potential, seismic quiescence, seismic hazard

\section{GíRiş}

Deprem oluşumlarının bölgesel ve zamana bağlı değişimlerinin istatistiksel olarak analizi, deprem istatistiğinde farklı parametreler kullanılarak yapılabilir. Bununla birlikte, sismotektonik aktivitelerin bölgezaman değişimlerini ortaya koyabilmek için geliştirilmiş oldukça etkili birçok yöntem mevcuttur. Depremselliğin nicel bir analizi için sismotektonik $b$-değeri ve öncü sismik durgunluk $Z$-değeri gibi temel ve en s1k kullanılan parametreler tercih edilebilir.

Deprem oluşumlarının magnitüd-deprem sayısı ilişkisi deneysel olarak tanımlanmış olup, Gutenberg-Richter ilişkisinin $b$-değeri olarak bilinmektedir [1]. Güçlü/büyük deprem oluşumlarının oluşma olasılıklarının ve tekrarlama zamanlarının tahmini oldukça önemli olduğundan, bu ölçek yasası dağılımı deprem istatistiğinde, istatistiksel sismolojide ve deprem tehlike çalışmalarında oldukça yaygın bir şekilde kullanılmaktadır. $b$-değerinin bölge-zaman dağılımları sismotektonik yapıların tanımlanması, gerilmenin bölge-zaman-derinlik değişimlerinin ortaya konması, büyük ve küçük depremlerin rölatif oranlarının analizi gibi birçok değerlendirmeye imkan sağlamaktadır [2]. Genel bir ifadeyle, bir bölge için $b$-değerinde, hem bölgesel hem de zamansal olarak, bir azalma söz konusu 
ise deprem oluşma olasılığından bahsedilebilir. Depremselliğin bölgesel ve zamana bağlı değişimlerini tanımlamada kullanılan bir diğer önemli uygulama ise depremsellik oran değişimlerinin analiz edilmesi olarak verilebilir. Öncü sismik durgunluk (Z-değeri), bir bölgedeki önceki ortalama deprem aktivitesine kıyasla mevcut deprem aktivitesindeki önemli bir düşüş olarak tanımlanır [3]. Bu durgunluk periyodu, deprem odak bölgesinde ve civarında, ana şoktan önceki birkaç yıl içerisinde görülebilir ve deprem sayısındaki bu azalma, depremsellikteki artışla, nispeten kısa bir periyod ile ana şoktan ayrılabilir [4]. Sonuçta, deprem sayılarındaki azalma dönemleri güçlü bir şekilde sismik ve tektonik yapılara bağlı olduğundan, depremsellik oran değişimleri sismik tehlike çalışmaları için önemli bir adımı teşkil etmektedir.

$\mathrm{Bu}$ çalışmanın temel amacı, yukarıda bahsedilen parametreler kullanılarak, detaylı sismotektonik çalışmaların ve tehlike analizlerinin yapılmadığ Türkiye'nin Orta Anadolu Bölgesi (OAB) ve civarını kapsayan alanda, deprem oluşumlarının bölgesel ve zamana bağlı değişimlerinin güncel ve güvenilir bir değerlendirmesini yaparak, deprem riski ve tehlikesi için ön bilgiler sağlamaktır. Bu tür parametreler Türkiye'nin ve dünyanın farklı bölgeleri için yapılan birçok istatistiksel çalışmada kullanılmış ve son yıllarda önemli sonuçlar elde edilmiştir [5-12].

\section{Orta Anadolu Bölgesi Ve Civarının Depremselliği Ve Tektonik Özellikleri}

Türkiye'nin OAB ve civarı kısa ve orta vadede büyük veya yıkıcı depremlerin oluşumu açısından önemli bir deprem tehlikesine sahip değildir. Bununla birlikte, geçmişte ve yakın zamanda $\mathrm{OAB}$ ve civarında 4 Temmuz 1978 Bala-Ankara (M5.3), 21 Nisan 1983 Bala-Ankara (M5.0), 27 Haziran 1998 HasanbeyliAdana (M6.3), 25 Haziran 2001 Arslanlı-Osmaniye (M5.5), 14 Aralık 2002 Andırın-Kahramanmaraş (M5.6), 20 Aralık 2007 Bala-Ankara (M5.7) ve 10 Ocak 2016 Hacıduraklı-Kırşehir (M5.1) gibi bazı güçlü/büyük depremler meydana gelmiştir. Dolayısıyla, son yıllardaki güçlü/büyük deprem oluşumları nedeniyle OAB için deprem tehlikesi çalışmaları daha da önemli hale gelmiştir.

OAB, Türkiye'nin Anadolu bloğundaki en önemli tektonik sistemlerinden biridir. Doğudan gelen sıkıştırma ve batıya doğru olan genişleme rejimleri bu bölge üzerinde oldukça etkilidir. $\mathrm{OAB}$ ve civarında $\mathrm{KG}$ ve KKD-GGB kısalması baskındır ve Kıbrıs boyunca Anadolu ve Afrika levhaları arasındaki çarpışmalı hareketler bu kısalma üzerinde oldukça etkilidir [13]. $\mathrm{OAB}$ ve civarındaki ana tektonik yapılar Tuzgölü Fay Zonu (TGFZ), Orta Anadolu Fay Sistemi (OAFS), Karsant1-Karaisalı Fay Zonu (KKFZ), Akpınar Fayı (AF), Niğde Fayı (NF) ve Salanda Fayı (SF) olarak verilebilir. Ayrıca, çalışma alanı sınırları içerisinde kuzeyde Kuzey Anadolu Fay Zonu (KAFZ), YağmurluEzinepazarı Fay Zou (YEFZ) ve Taşova-Çorum Fay Zonu (TÇFZ), batıda Beyşehir Grabeni (BG), Akşehir
Fay Zonu (AFZ) ve Akşehir-Afyon Grabeni (AAG), güneydoğuda Yakapınar-Göksun Fay Zonu (YGFZ), Karataş-Osmaniye Fay Zonu (KOFZ), Doğu Anadolu Fay Zonu (DAFZ), Bozova Fayı (BZF) ve Ölüdeniz Fay Zonu (ÖDFZ), güneybatıda Mut Fay Zonu (MFZ) ve doğuda ise Sürgü Fayı (SRF), Malatya Fayı (MF) ve Ovacık Fayı (OF) mevcuttur. Hem genişleme hem de sıkıştırma içeren bu fay sistemleri çoğu sağ yönlü ve sol yönlü doğrultu atımlı faylardan oluşan oblik atımlı fay sistemlerinden meydana gelmiştir. OAB için sismik ve tektonik detaylar farklı çalışmalarda ele alınmıştır [1315]. OAB için temel tektonik hatlar farklı çalışmalardan $[13,16,17]$ derlenmiş ve Şekli 1'de verilmiştir.

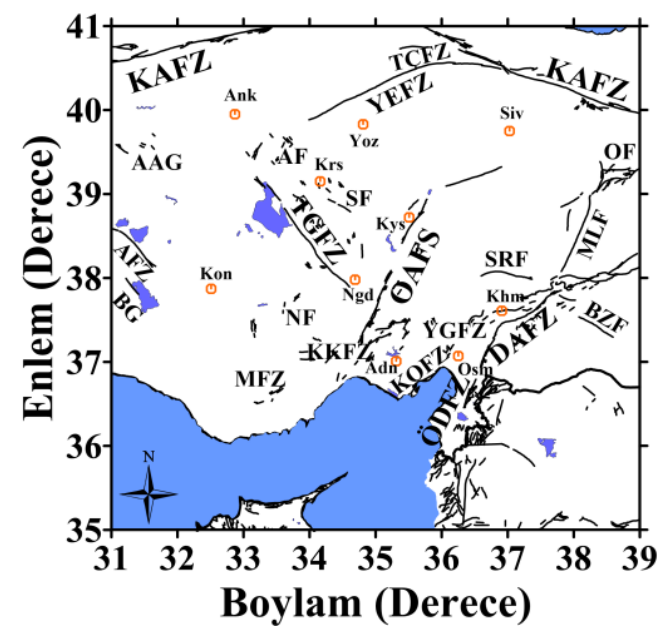

Şekil 1. OAB ve civarı için temel tektonik yapılar $[13,16,17]$. Fay isimleri metin içerisinde verilmiş, çalışma alanı sınırları içerisinde kalan bazı önemli yerleşim merkezleri şekil üzerinde gösterilmiştir: Ank: Ankara, Yoz: Yozgat, Siv: Sivas, Krs: Kırşehir, Kys: Kayseri, Kon: Konya, Ngd: Niğde, Khm: Kahramanmaraş, Osm: Osmaniye, Adn: Adana

\section{MATERYAL ve YÖNTEM}

Bu çalışma kapsamında, 1970-2006 yılları arasındaki depremler için kullanılan katalog Öztürk [13]'ten alınmıştır. Ayrıca, 2007-2019 yılları arasındaki deprem verisi Boğaziçi Üniversitesi, Kandilli Rasathanesi ve Deprem Araştırma Enstitüsü (KRDAE) ile Afet ve Acil Durum Yönetim Başkanlığı (AFAD) web sayfalarından temin edilen kataloglardan derlenmiştir. İstatistiksel bölge-zaman analizleri için Eylül 1974-Aralık 2018 yılları arasında magnitüdü 1.0-6.0 arasında değişen 16702 sı ̆̆ depremi (derinlik $<70 \mathrm{~km}$ ) içeren katalog kullanılmıştır. Kullanılan deprem kataloğu süre magnitüdü $M_{\mathrm{d}}$ 'ye göre homojen ve yaklaşık 44.29 yıllık bir zaman aralığı içerisinde süreklidir. Analizlerde kullanılan ve 16702 depremi içeren orijinal deprem kataloğu farklı magnitüd grupları için farklı semboller kullanılarak Şekil 2'de gösterilmiştir.

Deprem istatistiği çalışmalarında deprem verisindeki bağımlı ve bağımsız olayların birbirinden ayırt edilmesi güvenilir ve yüksek kaliteli deprem tehlikesi analizleri için önemli bir adımdır. Dolayısıyla, deprem katalogları ayrıştırılmalı (decluster, decompose) ve depremler birincil ve ikincil olaylara ayrılmalıdır. $\mathrm{Bu}$ işlem 
sonrasında tüm bağımlı olaylar bağımsız olaylardan ayrılır ve bu bağımlı depremler her bir kümeden çıkarılarak tek bir olaya atfedilir. $\mathrm{Bu}$ çalışma kapsamında, deprem kataloğunu ayrıştırmak için ZMAP yazılımı [18] ile Reasenberg [19] tarafindan geliştirilen algoritmaya dayalı ayrıştırma yöntemi kullanılmıştır. Buna ek olarak, tamlık magnitüdü (Mc-değeri), istatistiksel depremsellik çalışmalarında oldukça önemli bir parametredir. $M c$-değeri, tam bir deprem kaydının minimum büyüklüğüdür ve depremlerin magnitüddeprem sayısı dağılımı için hesaplanabilir [20]. Katalogdaki depremlerin \%90'ını içeren bu değerdeki zamana bağlı değişimler, özellikle $b$-değeri ve $Z$-değeri başta olmak üzere birçok depremsellik parametresinin hesaplanmasını etkiler. Deprem kayıt ağının depremden hemen sonra kurulamayışı yüksek aktivite süresince küçük olayların kayıt edilmesini zorlaştırır ve dolayısıyla kataloğun ilk dönemlerinde $M c$-değeri yüksek olur. $M c$-değerinin tahmini, magnitüd-deprem sayısı dağılımına ve $M c$-değerinin yaklaşık ilk dizisi olarak bu dağılımın ilk türevinin maksimum değer hesabına dayanır [20]. Her bir pencere başına belli sayıda deprem dikkate alınarak bu deprem dizisi için ortalama bir magnitüd değeri hesaplanmış ve her bir pencere için hesaplanan bu değer o pencereyi kapsayan zaman aralığı için ortalama $M c$-değeri olarak kabul edilmiştir. Dolayısıyla, $M c$-değerinin hesabı üst üste binen hareketli pencere tekniği kullanılarak maksimum olasılık yöntemiyle zamanın bir fonksiyonu olarak hesaplanabilir. Sonuçta, tüm istatistiksel parametrelerin analizlerinin yüksek kalitedeki sonuçları için katalogdaki maksimum deprem sayısının kullanılması hedeflenmiştir. Bu çalışmada tüm istatistiksel bölgezaman analizleri Wiemer [18] tarafindan sağlanan ZMAP yazılım programı ile yapılmıştır.

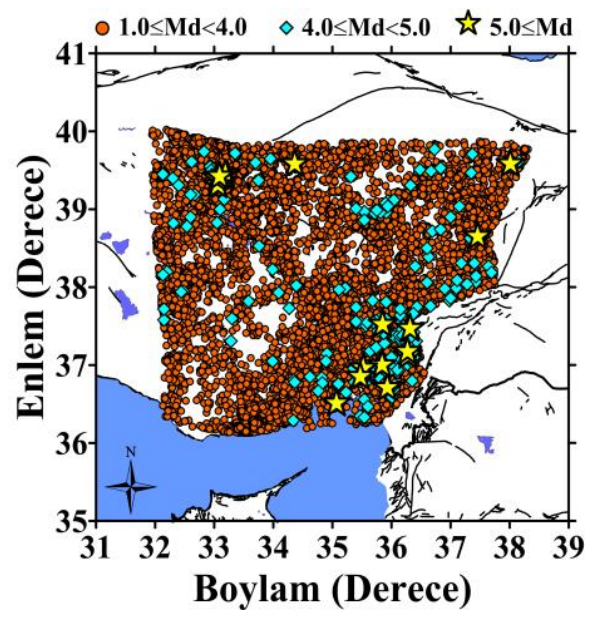

Şekil 2. OAB ve civarı için 1974-2019 yılları arasında $M_{\mathrm{d}} \geq 1.0$ olan 16702 sı̆̆ depremi içeren orijinal deprem kataloğunun episantr dağılım haritası. Depremlerin magnitüd değerleri farklı sembollerle gösterilmiştir

Ayrıştırma işleminden sonra, 1595 deprem (kataloğun yaklaşık \% 9.55'i) katalogdan çıkarılmış ve geriye 15107 deprem kalmıştır. $M_{\mathrm{d}} \geq 1.0$ olan ve sı̆̆ depremleri içeren orijinal deprem kataloğu için $M c$-değeri 1974-
2019 periyodunda 1.7 ile 3.6 arasında değişim göstermekte olup (Şekil 3), buna bağlı olarak $M c$-değeri ortalama 2.6 olarak alınmıştır. $M c$-değeri, $b$-değerinin ve $Z$-değerinin doğru olarak tahmin edilmesinde oldukça etkili olduğu için zamana bağlı $M c$ değişimleri analiz edilmiş ve dikkatli bir şekilde tahmin yapılmıştır. $M_{\mathrm{d}}<2.6$ olan depremlerin sayıs 8633 olup, bu değere sahip tüm depremler katalogdan çıkarılmıştır. Dolayısıyla, ayrıştırma işlemi ve $M_{\mathrm{d}}<2.6$ olan depremlerin katalogdan ayırt edilmesinden sonra, depremlerin toplamda yaklaşık \% 61.24'ü katalogdan çıkarılmış ve analizler için kullanılan deprem sayısı 6474'e düşmüştür (Şekil 4). Sonuç olarak, istatistiksel analizlerde daha homojen, tekdüze ve güvenilir deprem kataloğu kullanılmıştır.

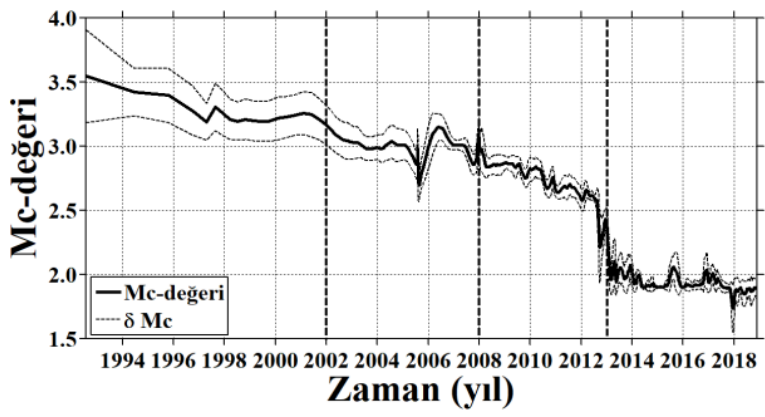

Şekil 3. Mc-değerinin zamana bağlı değişimleri. Tamlık magnitüdü analizi hareketli pencere tekniği ile örneklenmiştir ve her bir pencere 250 depremi içermektedir. Kesikli çizgi standart sapmayı $(\delta M c)$ göstermektedir

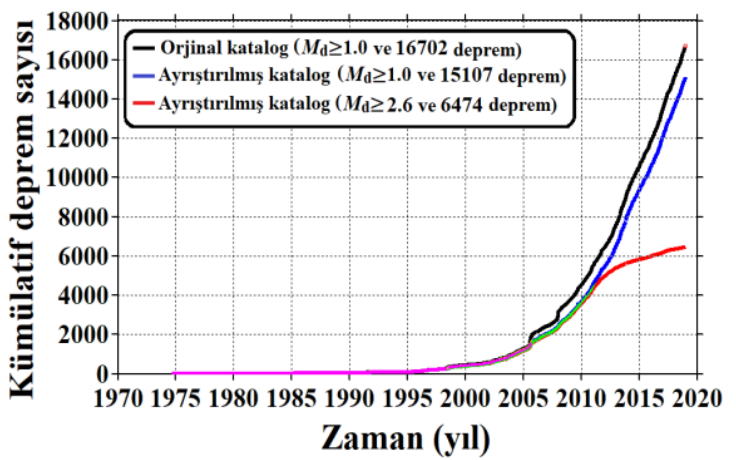

Şekil 4. $M_{\mathrm{d}} \geq 1.0$ olan tüm katalog için, $M_{\mathrm{d}} \geq 1.0$ ve $M_{\mathrm{d}} \geq 2.6$ olan ayrıştırılmış katalog için zamanın bir fonksiyonu olarak kümülatif deprem sayısı

\section{Magnitüd-Deprem Sayısı (Gutenberg-Richter İlişkisi, $b$-değeri)}

Gutenberg-Richter [1] boyut-ölçek ilişkisi (G-R) deprem istatistiğinin temel bağıntısı olarak bilinir. $\mathrm{Bu}$ deneysel güç yasası deprem oluşumlarının magnitüdfrekans dağılımını tanımlar ve matematiksel olarak aşağıdaki gibi ifade edilir:

$\log _{10} N(M)=a-b M$

Burada $N(M)$ magnitüdü $M^{\prime}$ 'den büyük veya eşit olan belirli bir dönem içerisindeki depremlerin kümülatif 
sayısı, $a$ ve $b$-değerleri ise sabitlerdir. $a$-değeri deprem aktivite seviyesindeki değişimleri gösterirken, magnitüd-deprem sayısı dağılımının eğimi $b$-değeri ile verilir. $a$-değeri farklı bölgeler için önemli değişimler gösterir ve bu değişimler çalışma alanının uzunluğuna, kataloğun periyoduna ve deprem sayısına oldukça bağımlıdır. $b$-değeri dünyanın farklı bölgeleri için 0.3 2.0 arasında değişim gösterir [21]. Bununla birlikte, G$\mathrm{R}$ bağıntısındaki ortalama $b$-değeri yaklaşık 1.0 olarak kabul edilir [22]. $b$-değeri küçük ve büyük depremlerin rölatif sayılarıyla ilişkili olmasına rağmen, $b$ değerindeki değişimleri etkileyen birçok faktör mevcuttur. Laboratuvar çalışmaları, $b$-değerindeki bir azalımın, kayma gerilmesindeki bir artışla ve basınçtaki bir azalmayla ilişkili olduğunu ortaya koymuştur [2,21,22,23]. Ayrıca, çatlak yoğunluğu, termal değişimler, jeolojik yapılar, fay uzunluğu, malzeme özellikleri, kayma dağılımları ve yamulma koşulları $b$ değerinde önemli değişimlere neden olur [2,23]. Sonuç olarak, $b$-değeri reolojik (cisimlerin gerilme altında zamana bağlı değişimleri) ve jeoteknik özellikler için ölçekten bağımsız temel bir parametredir.

\section{Standart Normal Sapma Z-testi (Öncü Sismik Durgunluk, Z-değeri)}

Depremsellik oran değişimlerini tanımlamak ve analiz etmek için birçok istatistiksel model mevcuttur. Bu yöntemlerin çoğu sismik durgunluğun ana depremlerden önceki bölgesel ve zamana bağlı modellemelerini kullanır. Bu tür depremsellik analizleri için en sık tercih edilen yöntemlerden biri standart normal sapma Z-testi olarak verilir. ZMAP tekniği sismik durgunluk gösteren alanları haritalamak için kullanılır [24]. Standart normal sapma Z-testi standart sapma birimindeki güven seviyesinin istatistiksel değerlendirmesi için Uzun Vadeli Ortalama (Long Term Average, LTA) üretir ve aşağıdaki denklem ile verilir:

$$
Z(t)=\frac{R_{1}-R_{2}}{\left(\frac{\sigma_{1}^{2}}{n_{1}}+\frac{\sigma_{2}^{2}}{n_{2}}\right)^{1 / 2}}
$$

Burada $R_{l}$ tüm ön pencere içerisindeki depremler için ortalama aktivite oranı, $R_{2}$ tüm arka plan penceresindeki depremler için ortalama depremsellik oranı, $\sigma$ ve $n$ ise sırasıyla standart sapmalar ile pencere içerisinde ve dışarısındaki örneklerin sayısıdır. Zamanın bir fonksiyonu olarak hesaplanan Z-değeri, deprem kataloğunun periyodu boyunca ön pencerenin belli zaman aralıkları ile kaydırılmasına ve her periyod için deprem aktivitesindeki değişimlerin haritalanmasına olanak sağlar.

\section{BULGULAR ve TARTISMA}

$\mathrm{Bu}$ çalışmada temel hedef, 2019 yılı başlangıcında Türkiye'nin $\mathrm{OAB}$ ve civarı için iki sismotektonik parametre $b$-değeri ve $Z$-değerinin bölgesel ve zamana bağlı değişimlerinin analiz edilmesiyle deprem tehlikesi ve riski için bazı ön değerlendirmelerde bulunmaktır. Bu tür kapsamlı istatistiksel analizler için bu çalışmada, deprem aktivitesinin zaman-magnitüd dağılımı, zamanla $M c$-değeri değişimi, $b$-değeri ve $Z$-değerinin bölgesel ve zamana bağlı değişimleri ile bu parametreler arasındaki ilişkiler irdelenmiştir. Sonuçta, OAB ve civarı için gelecek deprem oluşumları için kullanılabilir bilgiler ortaya koyarak güncel ve gelecek deprem potansiyeli belirlenmeye çalışılmıştır.

İstatistiksel bölge-zaman analizlerini içeren depremsellik çalışmalarında minimum magnitüdlü depremin seçimi için $M c$-değerinin tahmini oldukça önemlidir. Bu nedenle, $M c$-değerinin zamanla değişimi ve standart sapması hesaplanmış ve Şekil 3'te gösterilmiştir. Zamanın bir fonksiyonu olarak $M c$ değerinin tahmini hareketli pencere tekniği kullanılarak yapılmıştır. 16702 depremi içeren orijinal deprem kataloğu kullanılmış ve $M c$-değerinin tahmini için pencere başına 250 deprem ile örneklenmiştir. Zamanın bir fonksiyonu olarak $M c$-değerindeki değişimleri daha ayrıntılı olarak inceleyebilmek için katalog dört farklı zaman dilimine ayrılmış ve belirli periyodlardaki dalgalanmalar daha net ortaya konmuştur. $M c$-değeri 1974-2002 yılları arasında oldukça büyük (3.0-3.6) değişimler gösterirken, 2002-2008 yılları arasında 2.6'dan 3.0 civarına kadar değişmektedir. 2008'den 2013'e kadar 2.0-3.0 arasında değişim gösterirken, 2019 yılı başında yaklaşık 1.8 değerine kadar düştüğü görülür. Sonuç olarak, Şekil 3'te görüldüğü gibi $M c$ değeri 1974-2019 yılları arasında 1.7'den 3.6'ya kadar sabit olmayan bir değişim gösterir. $M c$-değerinin tahmini için yapılan bu analize göre, $M c$-değeri ortalama 2.6 olarak varsayılmış ve tüm parametrelerin tahmininde bu $M c$-değeri değeri kullanılmıştır.

$M_{\mathrm{d}} \geq 1.0$ olan ve tüm depremleri içeren orijinal katalog (16702 deprem), $M_{\mathrm{d}} \geq 1.0$ olan ayrıştırılmış katalog (15107 deprem) ve $M_{\mathrm{d}} \geq 2.6$ olan ayrıştırılmış katalog (6747 deprem) için zamanın bir fonksiyonu olarak kümülatif deprem sayısı Şekil 4'te verilmiştir. Şekil 4'te görüldüğü gibi 1974-1995 yılları arasında deprem aktivitesinde önemli bir değişik yoktur ve 1995-2000 yılları arasında çok az bir depremsellik değişimi mevcuttur. Bununla birlikte, 2000 yılı başta olmak üzere özellikle 2005 yılından sonra deprem aktivitesinde önemli bir artış görülmektedir. Ayrıca, deprem kataloğu ayrı ayr1 1974-1995, 1995-2005 ve 2005-2019 arsında homojen olarak değerlendirilebilir. Son yıllarda KRDAE ve AFAD istasyon sayılarının artması ile kayıt edilen minimum deprem büyüklüğü 2.6'ya kadar bir düşüş göstermiştir. Bazı araştırmacılar istatistiksel deprem çalışmalarında $M c$-değerinin kullanımı üzerine detaylı bölgesel ve zamana bağlı analizler gerçekleştirmiş ve $M c$-değerinin seçimi ile kataloğun ayrıştırma işlemi sürecinin deprem oluşumlarının tahmininde oldukça önemli bir aşama olduğunu ifade etmiştir [25,26]. Bu araştırmalar, $M c$-değeri analizinin mutlaka yapılması gerektiğini, artçı şok, öncü şok ve deprem yığılımı gibi ana şoka bağımlı tüm olayların katalogdan çıkarılması gerektiğini ortaya koymaktadır. Şekil 4'te görüldüğü gibi, $M_{\mathrm{d}} \geq 2.6$ olan ayrıştırılmış 
depremlere ait kümülatif deprem sayısı eğrisi orijinal kataloğa göre daha düzgün bir yönelime sahiptir. Sonuçta, bu iki işlem ile bağımlı olaylar orijinal katalogdan çıkarılarak istatistiksel bölge-zaman analizleri için bağımlı olaylardan temizlenmiş, daha güvenilir ve daha homojen bir katalog elde edilmiştir.

G-R ilişkisindeki $b$-değeri ve magnitüd deprem sayısı dağılımı, 15107 depremi içeren ayrıştırılmış katalog kullanılarak analiz edilmiş ve Şekil 5 'te verilmiştir. $b$ değeri, en küçük kareler tekniğine göre daha doğru bir tahmin sağlayacağından, maksimum olasılık yöntemi ile hesaplanmıştır [27]. Mc-değeri 2.6 alınarak 1974-2019 yılları arasındaki ortalama $b$-değeri $1.08 \pm 0.03$ olarak hesaplanmıştır. $b$-değerine ek olarak, standart sapma, $a$ değeri ve $M c$-değeri de şekil üzerinde verilmiştir. Yukarıda da ifade dildiği gibi, $b$-değeri küresel ölçekte bölgeden bölgeye 0.3-2.0 arasında değişir ve ortalama $b$-değeri 1.0'e yakın olarak kabul edilmesine rağmen, tektonik depremler 0.5-1.5 arasında değişen bir $b$-değeri ile temsil edilirler [22]. Sonuçta, OAB ve civarındaki deprem oluşumları için $b$-değeri G-R ilişkisi ile oldukça iyi temsil edilir.

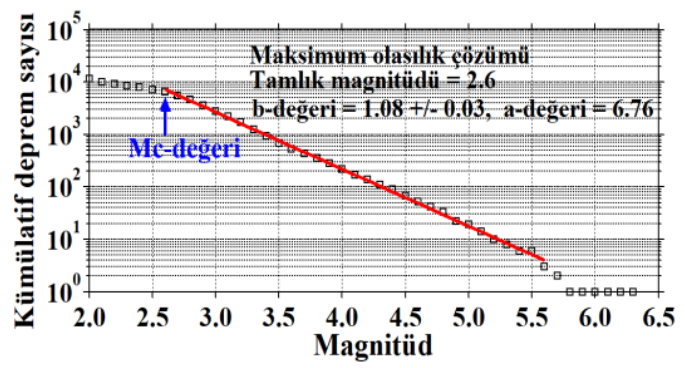

Şekil 5. G-R ilişkisindeki $b$-değeri ve magnitüd-deprem sayısı dağılımı. Analiz için 15107 depremi içeren ayrıştırılmış deprem kataloğu kullanılmış ve $M c$-değeri şekil üzerinde gösterilmiştir

$b$-değerinin zamana bağlı değişimleri Şekil 6'da verilmiştir. Zamanın bir fonksiyonu olarak $b$ değerindeki değişimleri daha ayrıntılı değerlendirebilmek için, belirli dönemlerdeki dalgalanmalar göz önünde bulundurularak, dört farklı zaman dilimi dikkate alınmış ve $b$-değerleri bu zaman aralıkları için hesaplanmıştır. $b$-değerinin zamanla değişimi ayrıştırılmış deprem kataloğu (15107 deprem) kullanılarak hesaplanmış ve 150 örneklik hareketli zaman penceresi kullanılmıştır. Bunun sonucunda, 2002, 2008 ve 2013 gibi belirli dönemlerde önemli artmalar ve azalmaların olduğu görülmüştür (Şekil 6). Buna bağlı olarak, Şekil 3 ve 7'de olduğu gibi, zamana bağlı değişiklikler dikkate alınarak zaman aralıkları 1974-2002, 2002-2008, 2008-2013 ve 2013-2019 olarak seçilmiştir. Her bir zaman aralığındaki deprem sayısı, zaman aralığının büyüklüğüne bağlı olarak farklı deprem sayıları ve $M c$-değerleri kullanılmıştır. 19742002 yılları arasında $b$-değerinde önemli değişimler olmamakla birlikte, ortalama $b$-değeri 534 deprem kullanılarak ve $M c=3.3$ alınarak $0.98 \pm 0.09$ olarak hesaplanmıştır. 2002-2008 yılları arasında $b$-değerinde büyük artma ve azalımlar görülmüş, ortalama $b$-değeri
1887 deprem kullanılarak ve $M c=3.0$ alınarak bir önceki periyoda göre daha büyük bir değer olan $1.58 \pm 0.03$ ile temsil edilmiştir. 2012 yılı başında keskin bir düşüş ile birlikte $b$-değerinde büyük dalgalanmalar ve 2008-2013 yılları arasında sistematik bir artış gözlenmiştir. Bu zaman periyodu için ortalama $b$-değeri 4098 deprem kullanılarak ve $M c=2.6$ alınarak bir önceki periyoda göre daha küçük bir değer olan $1.48 \pm 0.03$ ile temsil edilmiştir. Bununla birlikte, son zaman periyodu olan 2013-2019 yılları arasında $b$-değerinde belirgin bir azalma olup, ortalama $b$-değeri 8588 deprem kullanılarak ve $M c=2.0$ alınarak bir önceki periyoda göre daha düşük bir değer olan $1.25 \pm 0.05$ ile temsil edilmiştir. Genel olarak, Şekil 6'da görüldüğü gibi 2002-2012 yılları arasında $b$-değerinde belirgin bir artış gözlenirken, 2013 y1lından sonra belirgin bir azalma söz konusudur. Ayrıca, bu önemli dalgalanmalar 2000-2017 yılları arasındaki güçlü/büyük depremlerin oluşum zamanları ile ilişkilidir ve ana şok oluşumlarından önce $b$-değerindeki bu azalmalar net olarak görülebilir. Yukarıda bahsedildiği gibi, birçok araştırmacı bazı büyük depremlerin oluşumundan önce $b$-değerindeki bu tür düşüşleri gözlemlemiştir $[6,8,10]$. Bu sonuçlar dikkate alındığında, ana şoktan önce $b$-değerindeki düşüşün artan gerilme dağılımından kaynaklanabileceği düşünülebilir ve son yıllarda $b$-değerindeki bu azalım $\mathrm{OAB}$ ve civarında gelecekte olası bir depremin öncüsü olarak yorumlanabilir.

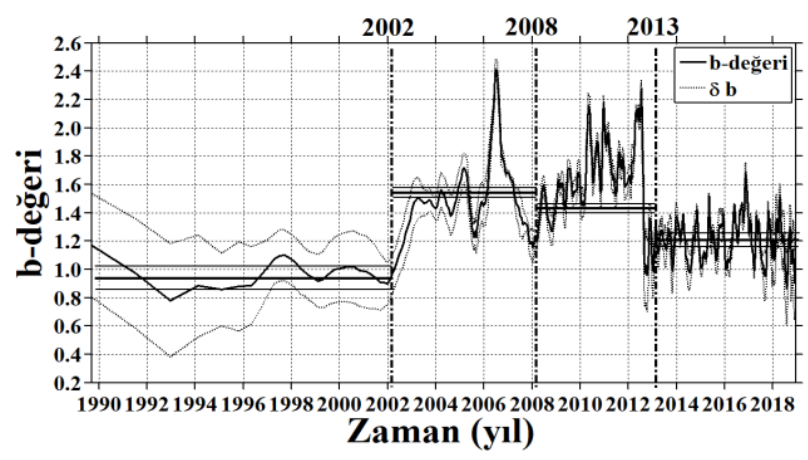

Şekil 6. Zamanın bir fonksiyonu olarak $b$-değeri ve standart sapması (kesikli çizgi, $\delta b$ ). Kalın yatay çizgiler ortalama $b$ değerlerini, alt ve üstteki ince yatay çizgiler bunların standart sapmalarını göstermektedir. Analiz için ayrıştırılmış deprem kataloğu kullanılmış ve hareketli pencere tekniği ile pencere bağına 150 deprem kullanılarak örnekleme yapılmıştır

1974-2019 yılları arasında OAB ve civarındaki depremlerin magnitüdlerindeki değişimleri değerlendirebilmek amaciyla, $M_{\mathrm{d}} \geq 4.0$ olan 216 depremin zamana bağlı değişimleri Şekil 7'de verilmiştir. 1974-2002 arasında ortalama magnitüd değeri $4.38 \pm 0.38,2002-2008$ arasında $4.38 \pm 0.44$, 20082013 arasinda $4.38 \pm 0.30$ ve $2013-2019$ yilları arasında $4.44 \pm 0.33$ olarak hesaplanmıştır. 1974-2002 y1lları arasinda $M_{\mathrm{d}} \geq 5.0$ olan 9 deprem bulunmakta olup, en büyüğü 6.3 iken, 2002-2008 yılları arasında 3 deprem ve en büyüğü 5.7, 2008-2013 yılları arasında 2 deprem ve en büyüğü 5.1, 2013-2019 yılları arasında 2 deprem ve en büyüğü 5.2'dir. Şekil 7'den görüldüğü gibi, 1974- 
1998 yılları arasında çok fazla güçlü deprem olmamasına rağmen, 1998 yılından sonra güçlü/büyük depremlerin sayısında önemli bir artış söz konusudur. Sonuçta, kümelenme özellikleriyle ilişkili depremsellik $O A B$ ve civarında güçlü/büyük bir deprem oluşumuyla ilişkili olabilir.

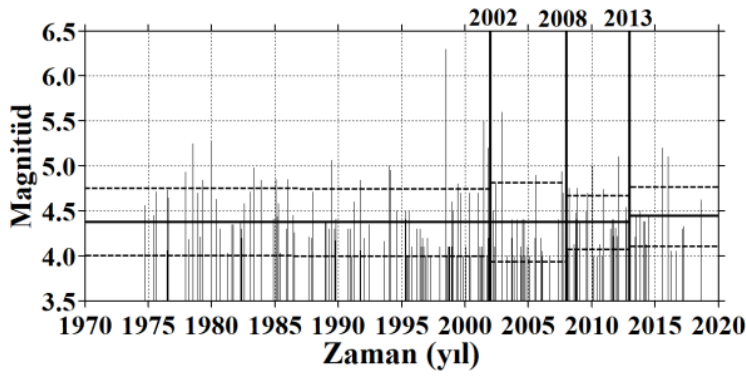

Şekil 7. 1970-2019 yılları arasında $M_{\mathrm{d}} \geq 4.0$ olan 216 deprem magnitüdünün zamanın bir fonksiyonu olarak değişimi. Kalın yatay çizgiler ortalama magnitüd değerlerini, alt ve üst ince yatay kesikli çizgiler ise bu zaman aralıkları için standart sapmaları göstermektedir

OAB ve civarı için $b$-değerinin 2008-2019 yılları arasındaki bölge-zaman değişimi Şekil 8'de verilmiştir. Bölge-zaman değişimlerini haritalamak için 15107 depremi içeren ayrıştırılmış deprem kataloğu kullanılmış ve çalışma alanı enlem ve boylam için $0.05^{\circ} \times 0.05^{\circ}$ lik grid aralıklarına bölünmüştür. Şekil 6 'da verilen zaman aralıkları dikkate alınarak 2008 2012 ve 2013-2019 yılları arasında $b$-değeri değişimleri hesaplanmış ve 2008-2019 yılları arasındaki fark ortaya konulmuştur. 2008-2012'ye kıyasla 2013-2019 yılları arasında $b$-değerinde bir azalma eğilimi görülmektedir. 2019 y1lı başlangıcında bazı bölgeler 0.5 ile -1.0 arasında değişen önemli azalımlar sergilemektedir. Bu bölgeler, NF ve civarı, KKFZ, MFZ ile KKFZ aras1, NF'nin güney batı ucu, OAFS'nin güney batı sonu, SRF ve civarı olarak verilebilir. Ayrıca, 2019 yılı başlangıcı itibariyle $b$-değerinde bazı küçük azalımlar (-0.4 ile -0.1 arası) ve artımlar da (0.1 ile 0.3 arası) söz konusudur.

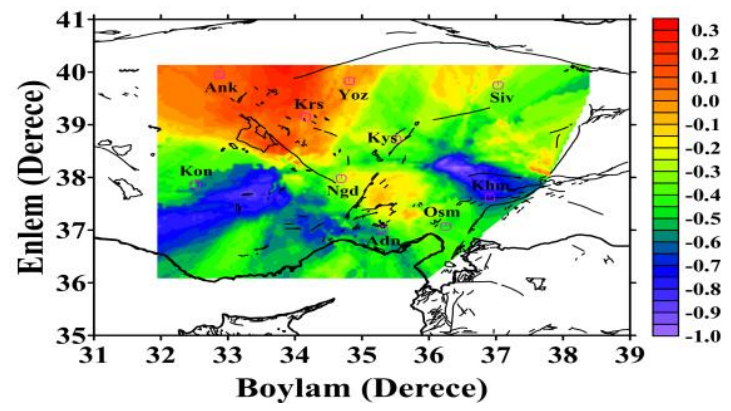

Şekil 8. OAB ve civarı için 2008-2019 yılları arasında zamansal $b$-değerinin bölgesel değişimi. Analizler için ayrıştırılmış deprem kataloğu kullanılmıștır

OAB için 2019 yılı başlangıcındaki depremsellik oran değişimleri Şekil 9'da sunulmuştur. $b$-değeri haritasında olduğu gibi $Z$-değerini de haritalamak için enlem ve boylamda $0.05^{\circ} \times 0.05^{\circ}$ 'lik bölgesel grid aralığ kullanılmıştır. 2019 yılı başlangıcında sismik durgunluk sergileyen anomali bölgeleri, TGFZ ile çalışma alanının kuzey batı uçlarında (B1), SF'nin kuzeydoğusunda ve SF ile OAFS arasında (B2), OAFS'nin kuzeydoğu kisımlarinda (B3), MLF'nin batisinda (B4), SRF ve civarında (B5), TGFZ ile OAFS arasında TGFZ'nin güneydoğu ucunda ve OAFS ile YGFZ arasında (B6), Tuzgölü'nün güneybatısında (B7) yoğunlaşmıştır. Dolayısıyla, Şekil 8 ve 9'da görüldüğü gibi, düşük $b$ değerli ve yüksek Z-değerli bölgelerin bir kombinasyonu $\mathrm{OAB}$ ve civarı için deprem potansiyelinin ortaya konulmasında kullanılabilir ön bilgiler sağlayabilir ve sonuçta, bu anomali bölgelerine dikkat edilmelidir.

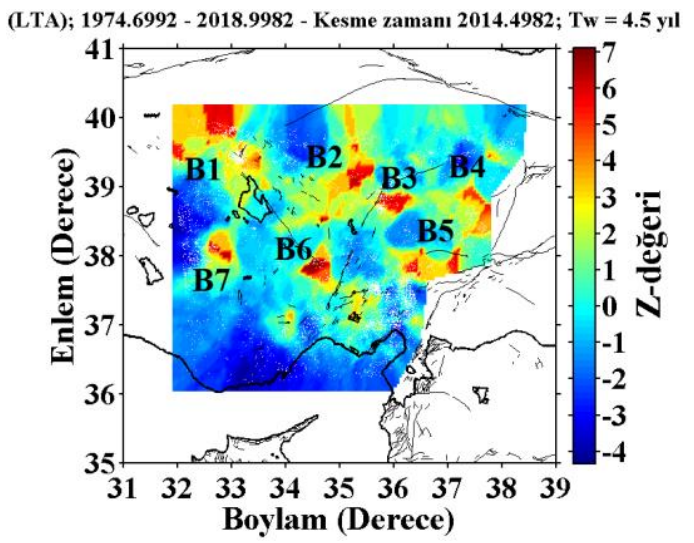

Şekil 9. OAB ve civarı için $T \mathrm{w}=4.5$ yıl alınarak 2019 yılı başlangıcı için hesaplanmış Z-değerinin bölgesel değişimleri. Analiz için $M_{\mathrm{d}} \geq 2.6$ olan ve 6474 depremi içeren ayrıştırılmış deprem kataloğu kullanılmıştır. Hesaplamaların zamanla daha yoğun ve sürekli olabilmesi için her bir grid aralığına düşen deprem sayısı 50 ve gruplama aralığ 28 gün olarak alınmıştır

OAB ve civarının güçlü deprem oluşumları ile ilişkili olarak k1sa/orta vadede yüksek seviyede bir deprem tehlikesine sahip olmadığı bilinmektedir. Buna bağlı olarak, OAB ve civarı için sismik ve tektonik parametreler arasındaki olası ilişkileri dikkate alan kapsamlı istatistiksel çalışmalar oldukça azdır ve deprem oluşumlarının bölge-zaman değişimleri üzerine fazla çalışma mevcut değildir. Bununla birlikte, bu bölgedeki son on yıldaki depremler dikkate alındığında, deprem dağılımlarının detaylı bir istatistiksel bölgezaman analizi önemli olacaktır. Bazı araştırmacılar farklı yöntemler kullanarak $\mathrm{OAB}$ ve civarındaki depremlerin istatistiksel davranışlarını tanımlamaya çalışmışlar ve önemli sonuçlar elde etmişlerdir $[28,29,30]$.

OAB'nin bazı kısımlarını kapsayan ve doğu Akdeniz bölgesini içeren bir alanda depremlerin geri dönüşüm periyodlarının ve deprem oluşum aralıklarının tahmini üzerine istatistiksel bir çalışma yapılmıştır [28]. Bu çalışma kapsamında Poisson, Gumbel ve Üstel dağılım modelleri gibi farklı istatistiksel yaklaşımlar kullanılmış ve çalışma alanı için G-R ilişkisindeki $b$-değeri 0.96 olarak hesaplanmıştır. Sismik risk ve tekrarlama zamanlarını içeren Poisson modeli sonuçlarına göre $\mathrm{Ms}=5.0$ (yüzey dalgası magnitüdü) olan depremlerin 10, $20,50,75$ ve 100 yıldaki oluşma olasılıkları sırasıyla 
$\% 75, \% 94, \% 99, \% 99$ ve $\% 100$ olarak hesaplanmıştır. $\mathrm{Ms}=5.5$ olan depremlerin 10, 20, 50, 75 ve 100 y1ldaki oluşma olasılıkları sırasıyla \%37, \%60, \%90, \%97 ve $\% 99$ olarak tahmin edilmiştir. Ayrıca, $\mathrm{Ms}=6.0$ olan depremlerin $10,20,50,75$ ve 100 yıldaki oluşma olasıl1klar1 ise sirasiyla $\% 14, \% 26, \% 53, \% 68$ ve $\% 78$ olarak elde edilmiştir. Bununla birlikte, $\mathrm{Ms}=6.4$ olan depremlerin $10,20,50,75$ ve 100 yıldaki oluşma olasılıkları sırasıyla $\% 6, \% 12, \% 27, \% 38$ ve $\% 47$ olarak tahmin edilmiştir. Bunlara ek olarak, Ms=5.0, 5.5, 6.0 ve 6.4 olan depremlerin geri dönüşüm periyodları sırasiyla 7.3, 21.8, 65.9 ve 159.6 y1l olarak hesaplanmıştır. $\mathrm{Bu}$ sonuçlardan görüleceği üzere, $\mathrm{OAB}$ ve civarındaki bazı bölgelerde orta/uzun vadede önemli bir deprem potansiyeli mevcuttur.

G-R ilişkisi dikkate alınarak, Türkiye'nin Batı Anadolu Bölgesi için, olasılığa dayalı bir deprem tehlike analizi yapılmış [29] ve 1900-2005 yılları arasındaki deprem verisi için maksimum olasılık yöntemi ile magnitüdfrekans ilişkisindeki $b$-değeri 0.84 olarak hesaplanmıştır. Poisson modeli sonuçlarına göre, $M \geq 5.0, M \geq 5.5$ ve $M \geq 6.0$ olan depremlerin 50,75 ve 100 yıldaki olasılıkları tüm magnitüd değerleri için $\% 100$ olarak hesaplanmıştır. Bununla birlikte, $\mathrm{M} \geq 6.5$ olan depremlerin 50, 75 ve 100 yıldaki olasılıkları sirasiyla \%94.8, \%98.8 ve \%99.7 olarak hesaplanırken, $\mathrm{M} \geq 7.0$ olan depremlerin 50, 75 ve 100 yıldaki olasılıkları sirasıly $\% 64.7, \% 81.4$ ve $\% 89.4$ olarak hesaplanmıştır. Ayrıca, $\mathrm{M} \geq 5.0, \mathrm{M} \geq 5.5, \mathrm{M} \geq 6.0, \mathrm{M} \geq 6.5$ ve $M \geq 7.0$ olan depremlerin geri dönüşüm periyodları sırasılla $1.3,3.5,9.8,27.1$ ve 75.1 yil olarak hesaplanmıştır. Bu sonuçlar, Batı Anadolu Bölgesi için orta/uzun vadede deprem potansiyeline işaret etmektedir ve bir önceki çalışmayla da uyumludur.

Özmen [30], 1900-2011 yılları arasındaki Mw $\geq 4.0$ (moment magnitüdü) olan depremleri kullanarak Türkiye'nin Orta Anadolu Bölgesi için istatistiksel bir deprem tehlikesi analizi gerçekleştirmiştir. $\mathrm{Bu}$ amaçla, deprem tehlike parametrelerini tahmin edebilmek için Gumbel Uç Değerler yöntemini kullanmış ve $30-35^{\circ} \mathrm{D}$ boylamları ile $38-41^{\circ} \mathrm{K}$ enlemleri arasında kalan bölgeyi altı alt bölgeye ayırarak bir değerlendirme yapmıştır. Her bir alt bölge için deprem olasılıkları ve tekrarlama periyodları hasara neden olabilecek ve gelecekte tekrarlayabilecek güçlü/büyük depremler için hesaplanmıştır. Farklı alt bölgelerin karşılaştırılması, KAFZ'nin $\mathrm{Mw} \geq 7.0$ olan depremin gelecek 100 ylldaki \%87 oluşma olasılığı ve 50 yıllık geri dönüşüm periyodu ile en yüksek deprem tehlikesine sahip olduğunu göstermiştir. Dolayısıyla, KAFZ depremlerle ilişkili tehlike için OAB ve civarı için önemli bir tetikleyici olabilir. Sonuç olarak bu çalışma, sismik tehlike çalışmalarına katkı sağlayabilir ve elde edilen sonuçlar bu bölgedeki deprem potansiyelinin değerlendirilmesinde öncül ve faydalı bilgiler ortaya koyabilir.

$\mathrm{Bu}$ çalışmada elde edilen sonuçlar ve literatürdeki mevcut bilgiler dikkate alındığında, son yıllarda OAB ve civarındaki depremlerin bölgesel ve zamana bağlı davranışlarının analiz edilmesiyle, yakın güncel ve yakın gelecekteki deprem tehlikesi açısından birincil ve kullanışlı sonuçlar ortaya konulduğu görülmektedir. $\mathrm{OAB}$ geçmiş ve yakın yıllarda büyük/yıkıcı depremlere maruz kalmamış olmasına rağmen, 14 Aralık 2002 Kahramanmaraş (M5.6), 20 Aralık 2007 Ankara (M5.7) ve 10 Ocak 2016 Kırşehir (M5.1) gibi bazı güçlü/büyük depremler çalışma bölgesi sınırları içerisinde meydana gelmiştir. Yukarıda bahsedilen araştırmacıların elde ettiği bulgulardan da görüleceği üzere, tüm sonuçlar birbirleriyle ve bu çalışmada elde edilen sonuçlarla uyumludur. Sonuç olarak, bu çalışmada tanımlanan sismik ve tektonik parametreler arasındaki detaylı bir istatistiksel bölge-zaman analizi Türkiye'nin OAB için orta/uzun vadede güçlü/büyük deprem oluşumları için deprem riski ve tehlikesinin ortaya konulmasında önemli bir bakış açısı sağlayabilir.

\section{SONUÇLAR}

$\mathrm{Bu}$ çalışma kapsamında Türkiye'nin OAB ve civarındaki güncel deprem dağılımlarının 2019 yılı başında bölgesel ve zamana bağlı davranışlarının istatistiksel bir değerlendirilmesi yapılmıştır. $\mathrm{Bu}$ amaçla, magnitüd-frekans dağılımındaki $b$-değeri ile sismik durgunluk $Z$-değeri gibi deprem istatistiğinde en sık kullanılan sismik ve tektonik parametreler analiz edilmiştir. 2008 y1lı başta olmak üzere, özellikle 2002 yılından sonra deprem aktivitesinde önemli bir artış söz konusudur ve katalogdaki depremlerin yaklaşık \%81.65'i 2008-2019 yılları arasında meydana gelmiştir. Orijinal katalog için tamlık magnitüdü $M c=2.6$ olarak alınmış ve tüm deprem oluşumları için ortalama $b$ değeri $1.08 \pm 0.03$ olarak hesaplanmıştır. $\mathrm{Bu}$ değer, ortalama $b=1.0$ değerine oldukça yakındır ve OAB ile civarındaki deprem oluşumlarının Gutenberg-Richter ilişkisi ile iyi temsil edildiğini göstermektedir. 20022008 yılları arasında $b$-değerinde gözle görülebilir bir artış (1.58 \pm 0.03$)$ söz konusudur. Buna karşın, 20082019 yılları arasında $b$-değerinde net bir düşüş gözlenmiştir. Ayrıca, 2008-2012 yılları arasında $b=1.48 \pm 0.03$, 2013-2019 y1llar1 arasında ise $b=1.25 \pm 0.05$ olarak hesaplanmıştır. Dolayısıyla, son yıllarda $b$-değerindeki azalma eğilimi, artan gerilme birikimiyle ve sonuçta da çalışma alanında gelecekteki olası bir depremle ilişkili olabilir.

Zamanın bir fonksiyonu olarak $b$-değerindeki bölgesel değişimler, 2013-2019 yılları arasında önemli azalmalar göstermiştir. $b$-değerinde düşüşlerin gözlendiği bölgeler, güney, bat1, güneybatı ve kuzeybatı yönleri boyunca NF ve civarını, MFZ, KKFZ ve KOFZ arasını, SRF ve civarı ile kuzeybatı kısımlarını, SRF ile DAFZ arasında kalan bölgeleri içermektedir. 2019 y1lı başlangıcında sismik durgunluk sergileyen yedi anomali bölgesi tespit edilmiştir. Yüksek Z-değerli bu bölgeler, çalışma alanının AF'yi içeren kısmı ve TGFZ'nin kuzeybatı sonları, SF'nin kuzeydoğusu, SF ile OAFS arası, OAFS'nin kuzeydoğu kısımları, MF'nin batısı, SRF ile DAFZ arası, TGFZ'nin güneydoğu ucu, KKFZ ve civarı, Tuzgölü'nün güneybatısı olarak verilebilir. Dolayısıyla, 2019 yılı başında OAB ve civarında 
tanımlanan düşük $b$-değerli ve yüksek $Z$-değerli bu anomali alanları gerilme artışı ile ilişkili olabilir ve gelecek güçlü/büyük depremler için en olası bölgeler olarak yorumlanabilir.

Sonuç olarak, sismik ve tektonik parametrelerin birlikte değerlendirilmesi ile $\mathrm{OAB}$ ve civarındaki deprem tehlikesi için, birincil ve kullanılabilir sonuçlar ortaya konulmuş ve elde edilen sonuçlar literatür çalışmalarıyla desteklenmiştir. Bu tür parametrelerin deprem istatistiği çalışmalarında birlikte değerlendirilmesi, potansiyel olarak farklı bölgelerdeki deprem tehlikesi çalışmalarına öncülük edecektir.

\section{TEŞEKKÜR}

ZMAP yazılımını sağlayan Prof. Dr. Stefan Wiemer'e (ETH, Zürich), yapıcı tavsiyelerde bulunan hakemlere ve editöre, analizlerde kullanılan deprem kataloğunu sağlayan KRDAE ve AFAD yetkililerine teşekkür ederim.

\section{KAYNAKÇA}

[1] Gutenberg B., Richter, C.F. Frequency of earthquakes in California, B. Seismol. Soc. Am. 34 185-188, 1944.

[2] Scholz C.H. The frequency-magnitude relation of microfracturing in rock and its relation to earthquakes, B. Seismol. Soc. Am. 58 399-415, 1968.

[3] Wyss M., Martirosyan A.H. Seismic quiescence before the M7, 1988, Spitak earthquake, Armenia, Geophysical Journal International 134(2) 329-340, 1998.

[4] Wyss M., Habermann R.E. Precursory seismic quiescence, Pure Appl. Geophys. 126(2-4) 319-332, 1988.

[5] Console R., Montuori C., Murru M. Statistical assessment of seismicity patterns in Italy: Are they precursors of subsequent events?, J. Seismol. 4 435-449, 2000.

[6] Polat O., Gok E., Yilmaz D. Earthquake hazard of the Aegean Extension region (West Turkey), Turkish Journal of Earth Sciences. 17 593-614, 2008.

[7] Katsumata K. Precursory seismic quiescence before the $\mathrm{Mw}=8.3$ Tokachi-oki, Japan, earthquake on 26 September 2003 revealed by a re-examined earthquake catalog, J. Geophys. Res. 116 B10307, 2011.

[8] Öztürk S. Characteristics of Seismic Activity in the Western, Central and Eastern Parts of the North Anatolian Fault Zone, Turkey: Temporal and Spatial Analysis, Acta Geophysica. 59(2) 209-238, 2011.

[9] Ali S.M. Statistical analysis of seismicity in Egypt and its surroundings, Arab. J. Geosci. 9:52, 2016.

[10] Öztürk S. Space-time assessing of the earthquake potential in recent years in the eastern Anatolia region of Turkey, Earth Sci. Res. J. 21(2) 67-75, 2017.

[11] Rodriguez-Perez Q., Zuniga F.R. Imaging b-value depth variations within the Cocos and Rivera plates at the Mexican subduction zone, Tectonophysics. 734-735 3343, 2018.

[12] Chiba K. Spatial and temporal distributions of b-values related to long-term slow-slip and low-frequency earthquakes in the Bungo Channel and Hyuga-nada regions, Japan, Tectonophysics. 757 1-9, 2019

[13] Bozkurt E. Neotectonics of Turkey-a synthesis, Geodinamica Acta. 14 3-30, 2001.

[14] Özsayin E., Dirik K. Quaternary activity of the Cihanbeyli and Yeniceoba fault zones: İnönü-Eskişehir fault system, Central Anatolia, Turk. J. Earth Sci. 16 471492, 2007.
[15] Gökten E., Varol B. General geology of the region and seismic sources. In Başokur, A. (eds) Geologicalgeophysical-geotechnical properties of soils west of the city of Ankara and dynamic behavior, Ankara University, pp.12-32 (in Turkish), 2010.

[16] Şaroğlu F., Emre O., Kuşcu O. Active fault map of Turkey, General Directorate of Mineral Research and Exploration. Ankara, Turkey, 1992.

[17] Ulusay R., Tuncay E., Sönmez H., Gökçeoğlu C. An attenuation relationship based on Turkish strong motion data and iso-acceleration map of Turkey, Eng. Geol. 74(3-4) 265-291, 2004

[18] Wiemer S. A software package to analyze seismicity: ZMAP, Seismological Research Letters. 72(3) 373-382, 2001.

[19] Reasenberg P.A. Second-order moment of Central California seismicity, 1969-1982, J. Geophys. Res. 90(B7) 5479-5495, 1985.

[20] Wiemer S., Wyss M. Minimum magnitude of completeness in earthquake catalogs: Examples from Alaska, the Western United States, and Japan, B. Seismol. Soc. Am. 90(3) 859-869, 2000.

[21] Utsu T. Aftershock and earthquake statistic (III): Analyses of the distribution of earthquakes in magnitude, time and space with special consideration to clustering characteristics of earthquake occurrence (1), Journal of Faculty of Science, Hokkaido University. Series VII (Geophysics) 3 379-441, 1971.

[22] Frohlich C., Davis S. Teleseismic b-values: Or, much ado about 1.0, J. Geophys. Res. 98(B1) 631-644, 12993.

[23] Mogi K. Magnitude-frequency relation for elastic shocks accompanying fractures of various materials and some related problems in earthquakes, Bulletin of the Earthquake Research Institute, Tokyo University. 40 831$853,1962$.

[24] Wiemer S., Wyss M. Seismic quiescence before the Landers $(M=7.5)$ and Big Bear $(M=6.5) 1992$ earthquakes, B. Seismol. Soc. Am. 84(3) 900-916, 1994.

[25] Katsumata K., Kasahara M. Precursory seismic quiescence before the 1994 Kurile Earthquake $(\mathrm{Mw}=8.3)$ revealed by three independent seismic catalogs, Pure Appl. Geophys. 155 43-470, 1999.

[26] Joseph J.D.R., Rao K.B., Anoop M.B. A study on clustered and de-clustered world-wide earthquake data using G-R recurrence law, International Journal of Earth Sciences and Engineering. 4 178-182, 2011.

[27] Aki K. Maximum likelihood estimate of $b$ in the formula $\log \mathrm{N}=\mathrm{a}-\mathrm{bM}$ and its confidence limits, Bulletin of the Earthquake Research Institute. Tokyo University 43237 239, 1965.

[28] Çobanoğlu İ., Bozdağ Ş., Dinçer İ., Erol H. Statistical approaches to estimating the recurrence of earthquakes in the Eastern Mediterranean region, İstanbul Univ. Eng. Fac. Earth Sci. J. 19(1) 91-100 (in Turkish with English abstract), 2006.

[29] Kahraman S., Baran T., Saatçı İ.A., Şalk M. The effect of regional borders when using the Gutenberg-Richter model, case study: Western Anatolia, Pure Appl. Geophys. 165 331-347, 2008.

[30] Özmen B. Assessment of the statistical earthquake hazard parameters for the Central Anatolia region, Turkey, Arab. J. Geosci. 8 6341-6351, 2015. 